\title{
Effect of Lactobacillus buchneri, Lactobacillus fermentum, Leuconostoc mesenteroides inoculants, or a Chemical Additive on the Fermentation, Aerobic Stability, and Nutritive Value of Crimped Wheat Grains
}

\author{
A. T. Adesogan, ${ }^{1 *}$ M. B. Salawu, ${ }^{* 2}$ A. B. Ross, ${ }^{\star}$ D. R. Davies, $†$ A. E. Brooks, $\dagger$ \\ ${ }^{*}$ IRS, University of Wales, Aberystwyth SY23 3AL, U. K. \\ †Institute of Grassland and Environmental Research, \\ Plas Gogerddan, Aberystwyth SY23 3EB, U. K.
}

\begin{abstract}
The preservation of crimped wheat grains by three bacterial inoculants or a chemical additive was compared. Crimped wheat grain [56.8 g dry matter (DM)/kg] was conserved in $1.75-\mathrm{kg}$ plastic bag, mini-silos without treatment, with $4 \mathrm{~L} /$ tonne of Crimpstore (CS; an additive containing a mixture of ammonium formate, propionate, ethyl benzoate, and benzoate, SAS Kelvin Cave, Ltd., UK) or $1 \times 10^{5} \mathrm{cfu} / \mathrm{g}$ of each of three inoculant additives containing Lactobacillus fermentum (A), Leuconostoc mesenteroides (B), and Lactobacillus buchneri (C). Six replicates were conserved per treatment. Ensiling DM losses, chemical composition, fermentation characteristics, and aerobic stability were measured in the silages after $68 \mathrm{~d}$ of ensiling. All the silages were well fermented and remained stable for $84 \mathrm{~h}$ after aeration. Subsequently, the rate of deterioration was slowest in crimped grains treated with CS treatment, followed by those treated with inoculant $\mathrm{C}$, while those treated with inoculant A deteriorated most rapidly. Residual water-soluble carbohydrate concentration was higher in crimped grains treated with CS than those treated with the inoculants. Ammonia nitrogen concentrations were lowest in CStreated crimped grains, followed by inoculants $\mathrm{C}$ and $\mathrm{A}$. DM losses were greater in CS-treated crimped grains than in crimped grains treated with inoculants A and C. In vivo digestibility was also measured in Texel-cross lambs fed a grass silage basal diet supplemented with the additive-treated crimped grains or a conventional, lamb finisher concentrate. Dry matter intake and digestibility were unaffected by treatment. In conclusion, bacterial inoculants containing $L$. buchneri are promising preservatives for crimped wheat grains.
\end{abstract}

\footnotetext{
Received August 19, 2002.

Accepted November 6, 2002.

Corresponding author: A. T. Adesogan; e-mail: adesogan@animal .ufl.edu.

${ }^{1}$ Current address: Department of Animal Sciences, University of Florida, P.O. Box 110910, Gainesville 32611, USA.

${ }^{2}$ Current address: Commonwork Farms, Ltd., Bore Place, Chiddingstone, Kent TN8 7AR, U.K.
}

(Key words: crimped grain preservation, Lactobacillus buchneri, Lactobacillus fermentum, Leuconostoc mesenteroïdes)

Abbreviation key: $\mathbf{C S}=$ Crimpstore additive, $\mathbf{A}=$ Lactobacillus fermentum $\left(1 \times 10^{5} \mathrm{cfu} / \mathrm{g}\right), \mathbf{B}=$ Leuconostoc mesenteroides $\left(1 \times 10^{5} \mathrm{cfu} / \mathrm{g}\right), \mathbf{C}=$ Lactobacillus buchneri NCIMB strain $40788\left(1 \times 10^{5} \mathrm{cfu} / \mathrm{g}\right), \mathbf{D M D}=\mathrm{DM} /$ digestibility, $\mathbf{D O M D}=\mathrm{DM}$ digestible $\mathrm{DM}, \mathrm{LAB}=$ lactic acid bacteria, $\mathbf{O M D}=$ OM digestibility, $\mathbf{W S C}=$ water-soluble carbohydrate.

\section{INTRODUCTION}

Unprocessed cereal grains in cattle rations are often under-utilized, because of the hardness of the seed coat, which limits starch digestibility. Physical processing can rupture the seed coat and increase starch availability, but the process is quite costly, and intake of excessive levels of processed mature grains can predispose cattle to acidosis. An alternative approach involves harvesting, crimping, and ensiling immature cereal grains. This approach leads to a higher density of desirable nutrients in the straw and grain, reduced risk of acidosis, increased yield due to reduced grain losses, and early sowing of subsequent (catch) crops (Shorrock, 1990). An additional advantage that is becoming increasingly important in the UK is that feeding crimped grains allows the use of homegrown, traceable (source-verified) feeds instead of purchased concentrates. However, to fully exploit the benefits of crimped grain, it is imperative that they are conserved in a way that minimizes ensiling losses. Two of the main additives used in the UK for conserving crimped grain are Graintona (FSL Bells, Ltd., Corsham, UK) and Crimpstore (CS; SAS Kelvin Cave, Ltd., Langport, Somerset, UK). Both of these are chemical additives, and there is very little published information on conserving crimped grains with microbial inoculants, which may be less corrosive and less costly. Therefore, this study was aimed at determining the effectiveness of three inoculants and Crimpstore at improving the fermentation and aerobic stability of crimped wheat grains. 
Supplementary studies also investigated the in vitro fermentation gas production characteristics of the crimped grains and the in vivo digestibility and voluntary feed intake in lambs of grass silage supplemented with the additive-treated crimped grains or a conventional concentrate.

\section{MATERIALS AND METHODS}

\section{Crimped Wheat Production}

Crimped wheat silages were prepared at the University of Wales, Aberystwyth, UK farm from a winter wheat (cultivar Savanna) crop harvested from a 30-ha field when the grain was at the cheesy ripe stage of maturity (56.8 $\mathrm{g} \mathrm{DM} / \mathrm{kg}$ ). The wheat crop was combined, and the grain was subsequently crimped by passing it through a mobile roller mill. The crimped wheat was conserved without treatment (control) or with $41 /$ tonne of Crimpstore (CS; an additive containing a mixture of ammonium formate, propionate, ethyl benzoate, and benzoate; SAS Kelvin Cave, Ltd., UK) or $0.1 \mathrm{~g} / \mathrm{kg}$ fresh weight of three inoculant additives. The inoculants contained $1 \times 10^{5} \mathrm{cfu} /$ $\mathrm{g}$ of fresh forage of Lactobacillus fermentum (A), Leuconostoc mesenteroides (B), and Lactobacillus buchneri NCIMB strain 40788 (C), (Lallemand Animal Nutrition, BP 59, Cedex, France). The additives were dissolved in $10 \mathrm{ml}$ of deionized water and sprayed in a fine mist on each of six replicate, $1.75-\mathrm{kg}$ grain samples. A similar quantity of deionized water was sprayed on the untreated grains. Each of the replicate-treated grain samples was placed in 200-gauge, $23 \times 33-\mathrm{cm}$ polythene bags. The bags were consolidated manually to expel air, secured tightly with plastic ties and tape (JAF Products, Somerset, UK), and stored at room temperature $\left(15\right.$ to $\left.19^{\circ} \mathrm{C}\right)$ for $68 \mathrm{~d}$. At silo opening, approximately $100 \mathrm{~g}$ of silage from the top of each silo was discarded. The remaining silage in each bag was then mixed and subsequently subsampled (200 g) for DM determination, laboratory analysis, and microbial enumeration. A further $300-\mathrm{g}$ sample was taken from each bag for the extraction of silage juice. The remaining silage in each of the six replicate bags per treatment were bulked together and thoroughly hand mixed. About $800 \mathrm{~g}$ of the mixed grain silage was used in quadruplicate for aerobic stability measurements. Each of the additives was also applied to $25 \mathrm{~kg}$ of crimped grain in triplicate and conserved in large polythene bag silos for the in vivo trial.

\section{Laboratory Analysis}

$\mathrm{pH}$ was measured directly on the silage juice using a $\mathrm{pH}$ meter (Jenway $3010 \mathrm{pH}$ meter; Kernick and Son, Ltd., Cardiff, UK). The silage juice was extracted with a Motorq 20 manually operated silage press (SP Tools,
England). Oven DM in fresh samples was determined by drying samples at $85^{\circ} \mathrm{C}$ for $48 \mathrm{~h}$. Dry matter losses were estimated by measuring differences in silo weights before and after ensiling. Total nitrogen concentration of fresh samples and soluble nitrogen (SN) in the silage juice were determined using the Kjeldahl procedure (AOAC, 1990), while the ammonia $\mathrm{N}$ in the juice was determined using the MAFF (1986) procedure. Neutral detergent fiber (NDF) and $\mathrm{ADF}$ were determined using the methods of Van Soest et al. (1991); NDF was determined using method A without the amylase step. Volatile fatty acids were determined by HPLC using the method described by Salawu et al. (1999). Water-soluble carbohydrate (WSC) and starch concentrations were determined respectively using the anthrone reaction assay (MAFF, 1986) and acid hydrolysis technique (Faithfull, 1990). Lactic acid bacteria (LAB) were enumerated in $1.0-\mathrm{ml}$ aliquots of the appropriate serial dilution added to pour plates of de Man Rogosa Sharpe Agar (MRS; Oxoid CM3611). Yeasts and molds were enumerated after 0.1$\mathrm{ml}$ aliquots were used to prepare spread plates of malt extract agar (MEA Oxoid CM59). Aerobic stability was measured using data loggers that recorded hourly temperature readings from thermocouple wires placed in four replicate $800-\mathrm{g}$ silage samples aerated in open-top polystyrene boxes. Aerobic deterioration was denoted by a $1^{\circ} \mathrm{C}$ rise above ambient temperature on graphs depicting silage temperature changes with time.

\section{In Vivo Trial}

Grass silage and animals. The in vivo trial was conducted according to the guidelines of the UK Ministry of Agriculture, Fisheries, and Food guidelines for the humane treatment of livestock. The trial was aimed at examining whether the grain silages could replace a standard concentrate supplement for lambs without jeopardizing their intake and digestion of the whole diet. The grass silage used was a first cut taken on May 7, 2001, from a perennial ryegrass pasture. The grass was mown, precision-chopped with a forage harvester to give a theoretical chop length of $2 \mathrm{~cm}$, and ensiled in concrete-walled bunker silos. After the silo was opened, sufficient quantities of the silage for feeding for $7 \mathrm{~d}$ were stored in a cold room $\left(4^{\circ} \mathrm{C}\right)$ from which daily feed allocations were taken. Thirty, 10-mo-old, Texel-cross wether lambs with an average weight of $35 \pm 2 \mathrm{~kg}$ were used for this work. The lambs were grouped according to body weight and assigned randomly to each treatment. Each lamb was housed individually in $1.2 \times 1.2 \mathrm{~m}$, open-sided pens with rubber matted floors and 24-h access to drinking water.

Treatments and feeding regime. Insufficient quantities of inoculant A were available for analysis in the in vivo trial. The grass silage basal diet was supplemented 
with approximately $265 \mathrm{~g} \mathrm{DM} / \mathrm{d}$ of lamb finisher pellets (Wynnstay Farmers PLC, Powys, UK) or the ensiled crimped grain treatments. The oil, CP, fiber, moisture, ash, vitamin $\mathrm{A}$, vitamin $\mathrm{D}$, vitamin $\mathrm{E}$, and selenium concentrations of the lamb finisher concentrate were 40,160 , and $100 \mathrm{~g} / \mathrm{kg} \mathrm{DM}, 135$ and $85 \mathrm{~g} / \mathrm{kg} \mathrm{DM}, 10,000,2,000$, and $40 \mathrm{IU} / \mathrm{kg}$, and $0.4 \mathrm{mg} / \mathrm{kg}$, respectively. The ingredients in the concentrate were wheat, wheatfeed, extruded sunflower meal, expelled palm kernel meal, sugar beet pulp, confectionary meal, molasses, extruded rape seed meal, salt, ammonium chloride, and calcium carbonate. The diets were fed in the fresh state, and the grass silage was offered at $110 \%$ of the previous days intake in order to achieve ad libitum intake. Each forage was fed twice daily at 0830 and $1600 \mathrm{~h}$. A vitamin mineral supplement was also fed at the rate of $10 \mathrm{~g} /$ head daily. The diets were fed for an acclimatization period of $14 \mathrm{~d}$ followed by a balance period of $7 \mathrm{~d}$. During the balance period, the daily forage DM intake of each animal was recorded, and total collections of feces were made for each animal. The apparent digestibility of DM (DMD), organic matter (OMD), crude protein, and NDF were measured in 20 of the lambs. In addition, digestible OM (DOM) in the DM (DOMD) and CP intake were calculated. Representative subsamples of each forage were analyzed for DM, CP, WSC, $\mathrm{NH}_{3} \mathrm{~N}, \mathrm{ADF}, \mathrm{NDF}$, and total ash.

\section{In vitro Fermentation Gas Production}

Fermentation gas production was determined on freeze-dried, milled (1-mm) samples using the method of Theodorou et al. (1994). Samples were incubated in triplicate for $0,3,6,9,13,17,21,26,31,37,47,55,71$, 99 , and $139 \mathrm{~h}$. The rumen fluid used was collected from two ruminally fistulated dairy cows grazed on a perennial ryegrass-dominated permanent pasture and supplemented daily with $2 \mathrm{~kg}$ of concentrate mix containing $3109 \mathrm{kcal} / \mathrm{kg} \mathrm{DM}$ of metabolizable energy and 916, 239, 185,330 , and $100 \mathrm{~g} / \mathrm{kg} \mathrm{DM}$ of OM, CP, NDF, starch, and WSC. Cumulative gas volumes from the fermentation of the additive-treated crimped grains and lamb finisher concentrate were fitted to the model of France et al. (1993), which is of the form $\mathrm{Y}=\mathrm{A}\{1-\exp [-\mathrm{b}(\mathrm{t}-\mathrm{T})+\mathrm{c}(\sqrt{\mathrm{t}} \mathrm{t}-$ $\sqrt{ } \mathrm{T})]$; ; where $\mathrm{Y}$ is cumulative gas volume $(\mathrm{ml}), \mathrm{A}$ is the asymptotic value for gas pool size ( $\mathrm{ml}), \mathrm{T}$ is the lag time (h) assumed to occur before degradation commences, $b$ $\left(\mathrm{h}^{-1}\right)$ and $\mathrm{c}\left(\mathrm{h}^{-1} / 2\right)$ are rate constants, and $\mathrm{t}$ is incubation time $(\mathrm{h})$. The fractional rate $\left(\mathrm{h}^{-1}\right)$ of gas production $(\mu)$ was calculated from the equation $\mu=\mathrm{b}+\mathrm{c} /(2 \sqrt{\mathrm{t}})$. After the incubations (after $139 \mathrm{~h}$ ), samples of the residual supernatant in each bottle were analyzed for $\mathrm{pH}$ and for VFA by HPLC.

\section{Statistical Analyses}

The effect of the additives on the fermentation and nutritive value indices was determined by ANOVA using a completely randomized design. The analyses were carried out using the general analyses of variance directive within the Genstat statistical package (Genstat V, 1997). Significance was declared at the 5\% level. Degrees of freedom for treatment were partitioned into preplanned orthogonal contrasts including: control vs other treatments, CS treatment vs inoculant treatments, inoculant $\mathrm{B}$ vs inoculants $\mathrm{A}$ and $\mathrm{C}$, inoculant $\mathrm{B}$ vs inoculant $\mathrm{C}$ and, for the in vivo trial, lamb concentrate supplement vs crimped grain supplements.

\section{RESULTS}

\section{Fermentation and Nutritional Characteristics}

All the additives reduced the $\mathrm{pH}$ and ensiling $\mathrm{DM}$ losses relative to the values for the control treatment (Table 1). The CS treatment was most effective at reducing the $\mathrm{pH}$, followed by inoculant C. However, CS treatment reduced ensiling DM loss by only $3.7 \%$ whereas inoculants $\mathrm{A}$ and $\mathrm{C}$ reduced such losses by 16.8 and $12.2 \%$, respectively. Irrespective of treatment, $\mathrm{NH}_{3} \mathrm{~N}$ concentration was low, but values for the inoculant treatments were lower than those for CS treatment. SN values were also lower $(P<0.05)$ in crimped grains treated with inoculant $A$ than in those treated with inoculants $B$ and C. Crimped grains treated with inoculants A and B had lower $(P<0.05)$ residual WSC concentration than the control. The CS-treated crimped grains had higher $(P<$ 0.05) residual WSC concentrations than those treated with the inoculants. The NDF concentration of crimped grains treated with inoculant $\mathrm{C}$ were lower than those treated with inoculants A and B. Starch, ADF, and CP concentrations and in vitro DOMD values were unaffected by treatment.

The acetate and ethanol concentrations in the control grains were lower than those that were additive-treated. Ethanol concentration was also higher in the CS and C treatments than in the inoculant treatments and treatment A, respectively. Lactate concentration was similar across the contrasts compared. The lactate-to-acetate ratios of the crimped grains were reduced by additive treatment, and the reduction was more pronounced $(P<0.001)$ in CS-treated crimped grains. In contrast, formic acid concentration was highest in CS-treated crimped grains. Neither propionate nor butyrate was detected in the crimped grains.

\section{Aerobic Stability and Microbial Counts}

All the inoculant treatments tended to increase the number of LAB relative to the control treatment (Table 
Table 1. Effect of inoculant treatment on the chemical composition of ensiled, crimped grains (g/kg DM or as stated).

\begin{tabular}{|c|c|c|c|c|c|c|c|c|c|c|}
\hline Treatment $^{1}$ & A & B & $\mathrm{C}$ & Control & CS & SED & $\begin{array}{l}\text { Control } \\
\text { vs. others }\end{array}$ & $\begin{array}{l}\text { CS vs. } \\
\mathrm{A}, \mathrm{B}, \& \mathrm{C}\end{array}$ & $\begin{array}{l}\text { B vs. } \\
\text { C \& A }\end{array}$ & C vs. A \\
\hline $\mathrm{DM}(\mathrm{g} / \mathrm{kg})$ & 570 & 566 & 569 & 566 & 564 & 1.37 & 0.473 & 0.001 & 0.011 & 0.404 \\
\hline DM loss (g/kg) & 38 & 45 & 40 & 45 & 44 & 0.51 & $<0.001$ & $<0.001$ & $<0.001$ & $<0.001$ \\
\hline $\mathrm{pH}$ & 4.10 & 4.12 & 4.09 & 4.14 & 4.05 & 0.01 & $<0.001$ & $<0.001$ & 0.028 & 0.540 \\
\hline Ammonia $\mathrm{N}^{2}$ & 72.8 & 81.9 & 75.2 & 81.8 & 85.1 & 2.92 & 0.196 & 0.002 & 0.005 & 0.413 \\
\hline Soluble $\mathrm{N}^{2}$ & 769.3 & 877.7 & 841.7 & 863.4 & 861.2 & 31.02 & 0.302 & 0.225 & 0.013 & 0.029 \\
\hline Starch & 680.8 & 663.2 & 669.0 & 667.2 & 679.8 & 14.48 & 0.602 & 0.462 & 0.358 & 0.422 \\
\hline $\mathrm{ADF}$ & 46.08 & 43.72 & 42.90 & 47.67 & 46.33 & 1.87 & 0.061 & 0.182 & 0.637 & 0.101 \\
\hline $\mathrm{NDF}$ & 129.3 & 133.6 & 111.9 & 119.8 & 119.7 & 6.03 & 0.434 & 0.302 & 0.020 & 0.008 \\
\hline $\mathrm{DOMD}^{4}$ in vitro & 813.2 & 822.3 & 819.7 & 806.8 & 812.2 & 6.01 & 0.045 & 0.216 & 0.266 & 0.289 \\
\hline
\end{tabular}

${ }^{1} \mathrm{CS}=$ Crimpstore-treated grain, $\mathrm{A}=$ Lactobacillus fermentum $\left(1 \times 10^{5}\right)$-treated grain, $\mathrm{B}=$ Leuconostoc mesenteroides $\left(1 \times 10^{5}\right)$-treated grain, $\mathrm{C}=$ Lactobacillus buchneri $\left(1 \times 10^{5}\right)$-treated grain, Control $=$ untreated grain.

${ }^{2}$ Measured as $\mathrm{g} / \mathrm{kg}$ total N.

${ }^{3} \mathrm{WSC}=$ water-soluble carbohydrate.

${ }^{4} \mathrm{DOMD}=$ digestible organic matter in the $\mathrm{DM}$.

${ }^{5}$ Others = additive-treated grains; SED = standard error of the difference between means .

2). Yeast and mold counts were unaffected by treatment. Irrespective of treatment, all of the crimped grains were stable for $84 \mathrm{~h}$ after the silos were opened (Figure 1). Afterwards, they all deteriorated, although at different rates. Inoculant-A treated crimped grains deteriorated at the fastest rate, followed by the controls. Treatment CS produced the most stable silages, followed by treatment C.

\section{In vivo Digestibility and Voluntary Feed Intake}

The grass silage had a relatively high lactic acid concentration, and low $\mathrm{pH}$ and $\mathrm{NH}_{3} \mathrm{~N}$ concentrations, indicating that it was well fermented (Table 3). However, the low CP and high NDF concentration of the grass silage shows that its nutritive value was relatively poor. Supplementation of the grass silage affected neither grass silage nor total DMI (Table 4). The coefficients of digestion of DM, OM, CP, and NDF of the total diets were similar across the treatments. However, starch digestibility was lower in the lambs that were supplemented with the concentrate and the control grains than in those supplemented with grains and the additivetreated grains, respectively. DOMD was also unaffected by treatment. Digestible OM intakes were numerically higher in lambs fed inoculant-C treated grain.

\section{Fermentation Gas Production}

Total gas production, the lag phase duration, and the concentrations of butyrate and total VFA were lower in the concentrate than in the grains (Table 5). Total gas production was also higher in the control grains than in additive-treated grains. Additive treatment increased

Table 2. Effect of additive treatment on the fermentation characteristics and microbial counts of ensiled, crimped grains (g/kg DM or as stated).

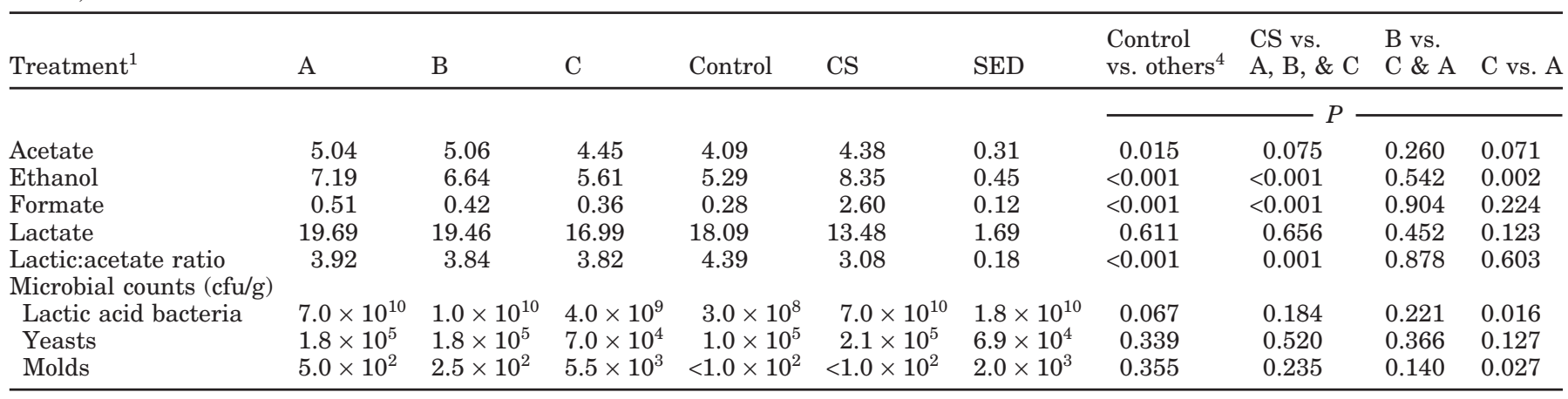

${ }^{1} \mathrm{CS}=$ Crimpstore-treated grain, $\mathrm{A}=$ Lactobacillus fermentum $\left(1 \times 10^{5}\right)$-treated grain, $\mathrm{B}=$ Leuconostoc mesenteroides $\left(1 \times 10^{5}\right)$-treated grain, $\mathrm{C}=$ Lactobacillus buchneri $\left(1 \times 10^{5}\right)$-treated grain, Control $=$ untreated grain.

${ }^{4}$ Others $=$ additive-treated grains; SED $=$ standard error of the difference between means. 


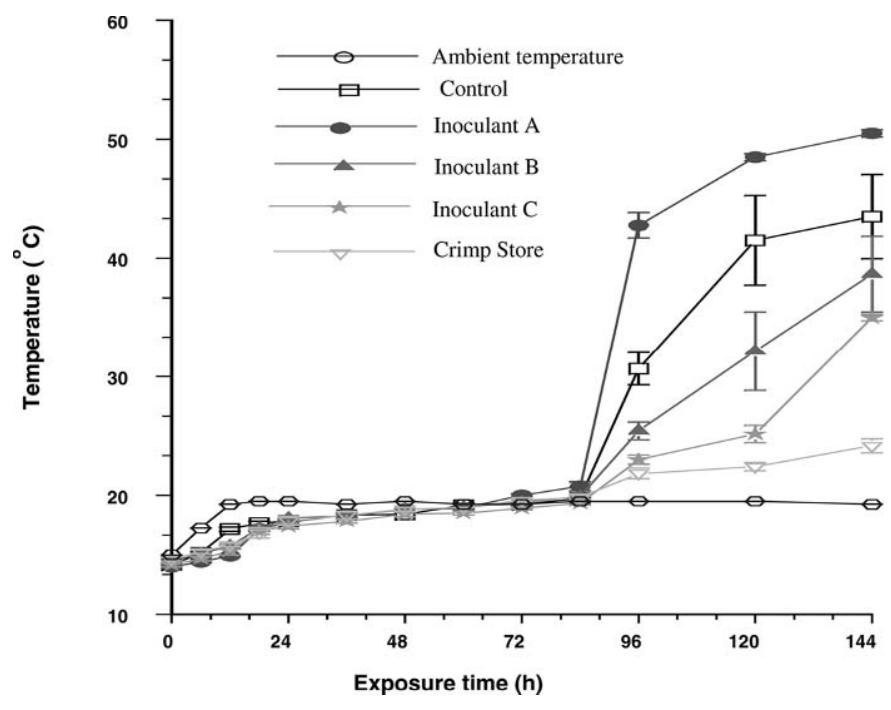

Figure 1. Effect of additive treatment on aerobic stability of crimped wheat grains. $\mathrm{CS}=$ Crimpstore, a buffered propionate preservative, $\mathrm{A}=$ Lactobacillus fermentum $\left(1 \times 10^{5}\right), \mathrm{B}=$ Leuconostoc mesenteroides $\left(1 \times 10^{5}\right), \mathrm{C}=$ Lactobacillus buchneri $\left(1 \times 10^{5}\right)$. Error bars indicate variability the $5 \%$ level of significance.

the lag phase in the grains. CS treatment produced lower residual $\mathrm{pH}$ values than the inoculant treatments. Compared with other inoculant-treated grains, inoculant Atreated grains had a higher residual $\mathrm{pH}$, shorter lag phase, slower degradation rate, lower total gas production, and lower concentrations of acetate, butyrate, and propionate. The ratios of lipogenic to gluconeogenic VFA [(Acetate + butyrate)/propionate] ratio and the acetateto-propionate ratio were also higher in the inoculant Atreated grains than in the other inoculant treatments.

\section{DISCUSSION}

All of the inoculant treatments contained obligate heterofermentative bacteria that use the 6-phosphogluconate/phosphoketolase pathway to ferment WSC into ace-

Table 3. Chemical composition of the grass silage (g/kg DM).

\begin{tabular}{lc}
\hline & Composition \\
\hline $\mathrm{pH}$ & 3.7 \\
$\mathrm{DM}(\mathrm{g} / \mathrm{kg})$ & 209 \\
Water soluble carbohydrates & 20 \\
Ash & 91 \\
Ammonia N (g/kg total N) & 43 \\
$\mathrm{CP}$ & 125 \\
$\mathrm{NDF}$ & 603 \\
In vitro digestible organic matter in the DM & 643 \\
Metabolizable energy (Kcal/kg DM) & 2495 \\
Effective rumen-degradable protein & 89.8 \\
Rumen-undegradable protein & 3.4 \\
Total VFA & 12.4 \\
Lactic acid & 131.7 \\
\hline
\end{tabular}

tate and ethanol (Dellaglio et al., 1995). The resulting DM losses were similar to the level that typifies the heterofermentation of glucose (McDonald et al., 1991). Nevertheless, all of the additives reduced the $\mathrm{pH}$ to levels at which the growth of undesirable microbes is curtailed, and they produced lower $\mathrm{pH}$ values and DM losses than the control. Despite these similarities, there were marked differences in the indices of fermentation efficiency between inoculants. Inoculant A produced residual WSC concentrations that were similar to those for the other inoculants, but it was the most effective inoculant at curtailing proteolysis and DM losses. It can, therefore, be considered to have given the most desirable fermentation. This may have been because the $L$. fermentum it contained is more acid-tolerant than many other bacteria. For instance, L. fermentum was shown to thrive under the acidic conditions imposed by an $80 \%$ cereal, 20\%-forage diet that inhibited other bacteria (Wells et al., 1997). Lactobacillus fermentum has also been found to be less fastidious and to grow faster than other lactate bacteria on wheat, barley, and malt media (Charalampopoulos et al., 2002). While the performance of inoculant C, which contained L. buchneri, was intermediate, among the inoculant treatments, inoculant B, which contained L. mesenteroides, produced the least desirable fermentation, as shown by the extent of proteolysis and DM losses. Leuconostoc spp. are important in the initial phase of the fermentation of wheat silages, but they are eventually superceded by other bacteria (Moon et al., 1981). They are characteristically less acidophilic than other bacteria, as their growth is curtailed at a $\mathrm{pH}$ of 5.4 to 5.7 (Dellaglio et al., 1995), which is higher than that ( $\mathrm{pH} 4$ or lower) which is necessary for minimizing proteolysis (Heron et al., 1989). These factors likely explain the poor performance of inoculant B.

CS was the most effective additive at enhancing residual WSC concentrations. This was probably because the organic acids in CS restricted the growth of LAB and undesirable bacteria that ferment WSC. This concurs with other studies in which organic acid treatment reduced WSC fermentation relative to heterofermentative inoculants (Mayne, 1993; Salawu et al., 2001; and Adesogan and Salawu, 2002). Surprisingly, CS treatment was less effective than inoculant treatment at reducing DM losses. This may have been because of the relatively high ethanol concentration in the CS-treated crimped grains, which often reflects the metabolism of WSC by yeasts. This is supported by the tendency for higher yeast counts in the CS-treated crimped grains. The high $\mathrm{NH}_{3} \mathrm{~N}$ concentration of the CS-treated crimped grains is due to the $\mathrm{NH}_{3} \mathrm{~N}$ concentration $(62 \mathrm{~g} / \mathrm{kg})$ of the $\mathrm{CS}$ additive rather than the extent of proteolysis. Once this is accounted for, the mean $\mathrm{NH}_{3} \mathrm{~N}$ concentration of the CS treatment becomes $50 \mathrm{~g} / \mathrm{kg} \mathrm{TN}$, which is lower than that which 
Table 4. Effect of inoculant treatment on the in vivo digestibility and voluntary feed intake of lambs fed on grass silage supplemented with concentrates or crimped grain.

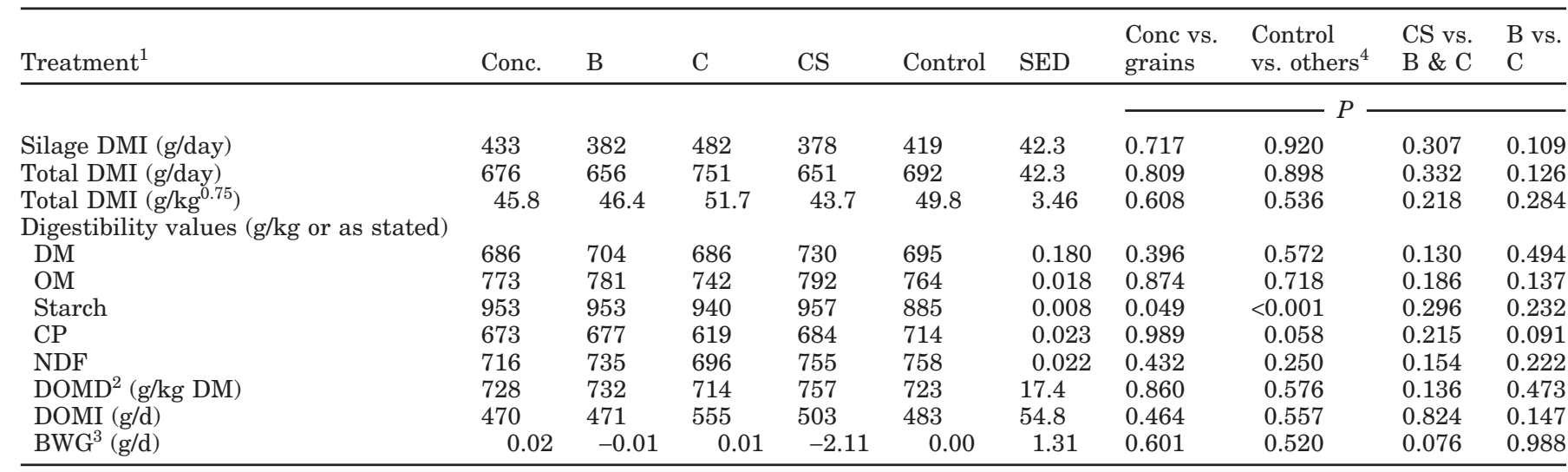

${ }^{1} \mathrm{CS}=$ Crimpstore-treated grain, Conc. = Lamb finisher pellets, $\mathrm{B}=$ Leuconostoc mesenteroides $\left(1 \times 10^{5}\right)$-treated grain, $\mathrm{C}=$ Lactobacillus buchneri $\left(1 \times 10^{5}\right)$-treated grain, Control $=$ untreated grain. Conc. $=$ Lamb finisher concentrate supplement.

${ }^{2} \mathrm{DOMD}=$ digestible organic matter in the DM.

${ }^{3} \mathrm{BWG}=$ body weight gain.

${ }^{4}$ Others $=$ additive-treated grains; SED $=$ standard error of the difference between means .

occurred in any of the other treatments. The CS treatment was, therefore, effective at curtailing proteolysis.

Unlike the crimped grains treated with inoculant A, those treated with CS, C, and B deteriorated at slower rates than the control. The slower deterioration of the CS-treated silage is probably because it contained high levels of formic acid in addition to the other antifungal acids in the additive. These acids seem to have prevented mold growth, but they did not completely deter the growth of yeasts and their conversion of WSC to ethanol.

The relatively high acetate levels in the inoculanttreated grains are due to their ability to convert glucose to acetate by heterofermentative pathways (McDonald et al., 1991), while that of the CS treatment suggests that the chemical preservative did not curtail the growth of heterofermentative, acetate-producing bacteria. The deterioration of the forages within $4 \mathrm{~d}$ is surprising given the presence of relatively high quantities of acetate, which is antimycotic (Moon, 1983; Higgins and Brinkhaus, 1999,). Adesogan and Salawu (2002) also found that although application of an L. buchneri inoculant increased acetate concentrations, it did not improve aerobic stability. This was ascribed to neutralization of acetate by the high buffering capacity of the peas in the pea

Table 5. In vitro fermentation gas production parameters and residual VFA concentrations for crimped grains and lamb finisher concentrate.

\begin{tabular}{|c|c|c|c|c|c|c|c|c|c|c|c|c|}
\hline Treatment $^{1}$ & Control & A & B & $\mathrm{C}$ & CS & Conc. & S.E.D. & $\begin{array}{l}\text { Conc vs. } \\
\text { grains }\end{array}$ & $\begin{array}{l}\text { Control } \\
\text { vs. others }\end{array}$ & $\begin{array}{l}\text { CS vs. } \\
\mathrm{A}, \mathrm{B}, \& \mathrm{C}\end{array}$ & $\begin{array}{l}\text { B vs. } \\
\text { A \& C }\end{array}$ & A vs. C \\
\hline \multicolumn{13}{|c|}{ Gas production parameters ${ }^{2}$} \\
\hline Rate constant $(/ \mathrm{h})$ & 0.094 & 0.085 & 0.094 & 0.095 & 0.093 & 0.095 & 0.003 & 0.185 & 0.202 & 0.325 & 0.092 & 0.002 \\
\hline Lag phase (h) & 3.43 & 0.74 & 3.73 & 3.75 & 3.48 & 1.84 & 0.15 & $<0.001$ & 0.001 & $<0.001$ & $<0.001$ & $<0.001$ \\
\hline Residual pH & 6.08 & 6.38 & 6.13 & 6.12 & 6.03 & 6.47 & 0.048 & 0.653 & 0.116 & 0.049 & 0.125 & $<0.001$ \\
\hline \multicolumn{13}{|c|}{$\begin{array}{l}\text { Residual volatile fatty acids } \\
\text { (VFA) (mM) }\end{array}$} \\
\hline Propionate (Pr) & 18.6 & 15.8 & 20.5 & 20.1 & 19.6 & 17.3 & 0.68 & 0.050 & 0.695 & 0.023 & 0.001 & $<0.001$ \\
\hline Isobutyrate & 0.64 & 0.82 & 0.72 & 0.74 & 0.74 & 0.74 & 0.05 & 0.867 & 0.011 & 0.655 & 0.207 & 0.125 \\
\hline Butyrate $(\mathrm{Bu})$ & 10.0 & 6.8 & 11.3 & 10.8 & 10.1 & 5.7 & 0.35 & $<0.001$ & $<0.001$ & $<0.001$ & $<0.001$ & $<0.001$ \\
\hline Isovalerate & 1.06 & 1.25 & 1.15 & 1.16 & 1.17 & 1.12 & 0.05 & 0.790 & 0.005 & 0.757 & 0.180 & 0.081 \\
\hline Valerate & 1.15 & 1.22 & 1.21 & 1.20 & 1.25 & 1.25 & 0.05 & 0.245 & 0.067 & 0.326 & 0.968 & 0.726 \\
\hline Ac:Pr ratio & 2.02 & 2.31 & 2.01 & 2.04 & 2.05 & 2.03 & 0.04 & 0.259 & 0.048 & 0.005 & $<0.001$ & $<0.001$ \\
\hline$(\mathrm{Ac}+\mathrm{Bu}) / \mathrm{Pr}$ & 2.60 & 2.79 & 2.60 & 2.62 & 2.60 & 2.38 & 0.04 & 0.986 & 0.895 & $<0.001$ & 0.024 & 0.004 \\
\hline
\end{tabular}

${ }^{1} \mathrm{CS}=$ Crimpstore-treated grain, $\mathrm{A}=$ Lactobacillus fermentum $\left(1 \times 10^{5}\right)$-treated grain, $\mathrm{B}=$ Leuconostoc mesenteroides $\left(1 \times 10^{5}\right)$-treated grain, $\mathrm{C}=$ Lactobacillus buchneri $\left(1 \times 10^{5}\right)$-treated grain, Control $=$ untreated grain.

${ }^{2}$ Others = additive-treated grains; SED $=$ standard error of the difference between means. 
wheat intercrop silages used. The deterioration observed in this study may have been due to the presence of acetate-tolerant molds and yeasts such as Geotrichum spp. (Higgins and Brinkhaus, 1999) and Hansenula canadensis (Moon, 1983). The stability of the control crimped grains in this study ( $3 \mathrm{~d}$ ) is similar to that observed in untreated, ensiled high-moisture corn (Dawson et al., 1998), and it indicates that additives may not be required for conserving crimped grains if the feedout rate is high. However, for longer-term storage, additives seem to confer an advantage on the aerobic stability of crimped grains.

The rapid deterioration in the inoculant A-treated crimped grains may have been due to higher substrate availability for lactate-utilizing yeasts or lower concentrations of more potent antimycotic acids that were not measured. Compared with the other inoculants, the slower deterioration rate conferred by inoculant $\mathrm{C}$ treatment which contained L. buchneri, agrees with previous findings in corn, wheat, and grass silages (Weinberg et al., 1999; Ranjit and Kung, 2000; Kung and Ranjit, 2001). However, unlike in these studies, the improved stability is not attributable to the stimulatory effect of $L$. buchneri on acetate production, since the acetate concentrations of crimped grains conserved with inoculant $\mathrm{C}$ were not greater than those resulting from the other inoculant treatments. Although L. buchneri can convert 1-2 propanediol to propionic acid, which is antimycotic, propionic acid was not detected in the grain silages. The rationale for the improved stability of the L. buchneri-treated grains, therefore, remains unclear.

Ranjit and Kung (2000) found that an L. buchneri inoculant applied at $1 \times 10^{6} \mathrm{cfu} / \mathrm{g}$ conferred greater stability on corn silages than a benzoate and propionate-based additive. However, when applied at $1 \times 10^{5}$, as was the case in this study, aerobic stability was slightly lower in silages treated with the inoculant. Kung and Ranjit (2001) also showed that when applied at less than $5 \times$ $10^{5} \mathrm{cfu} / \mathrm{g}, \mathrm{L}$. buchneri inoculants did not improve aerobic stability. Therefore, the poorer performance of the $L$. buchneri inoculant compared with CS may be attributable to the low inoculation rate.

The in vivo digestibility trial revealed that the intake and digestibility of most of the dietary components was unaffected by replacing the standard concentrate with the crimped grains. It is interesting to note that numerically, silage and total DMI were highest in lambs supplemented with inoculant C-treated grain, which contained L. buchneri and relatively high acetate concentrations. Therefore, contrary to previous suggestions (McDonald et al., 1991), feeding of high-acetate silages did not depress intake. Because only the supplementary part of the diet contained high-acetate concentrations, more work is needed on the effect of $L$. buchneri treatment and, hence, high-acetate concentration on feed intake in ruminants.

The fact that CS treatment produced numerically higher coefficients of DM, OM, and CP digestibility than the other treatments, may be related to the cellulolytic properties of the ammonia in the CS. However, this effect was not significant, and DOM intakes were unaffected by treatment. It is noteworthy that supplementation with the control grains or with the concentrate produced lower starch digestibility values. Czarnecka et al. (1991) also found that preservatives like ammonia and propionate increased protein digestibility and the amylolytic susceptibility of starch in cereal grains. Compared with the untreated grains, the additives may have improved starch digestibility by increasing the permeability of the endosperm or enhancing the degradation of the protein matrix surrounding the endosperm through their proteolytic action. The treatments were evidently required for making the starch in the grains as digestible as that in the concentrate supplement.

The fermentation gas production results suggest that microbial colonization and initial substrate utilization were greater in the grains treated with inoculant $\mathrm{A}$ and the lamb finisher concentrate. This suggests that the readily fermentable fractions in these treatments were more accessible. Surprisingly, these treatments showed the lowest rates and extents of gas production as well as the lowest total VFA concentrations. The reason for this is unclear and merits further investigation. Nevertheless, the VFA molar ratios are typical of those found in high-concentrate diets where the proportion of propionate is enhanced at the expense of acetate (McDonalds et al., 1995; Hristov et al., 2001). The total VFA concentrations were at the lower end of the normal range (70 to $150 \mathrm{mM}$; McDonald et al., 1995), and the residual $\mathrm{pH}$ values were higher than those denoting subacute clinical acidosis (Goad et al., 1998). Despite these findings, the CS-treated grain silages were more acidotic than the other treatments. The concentrate supplement was less acidotic than the crimped grains and had the lowest acetate:propionate and lipogenic:gluconeogenic acid ratios, which indicates a more efficient fermentation. Because these studies were collected on rumen fluid obtained after $139 \mathrm{~h}$ of fermentation, similar studies should be done using rumen fluid collected at times that more closely reflect the retention time of grains in the rumen of cows.

The higher isobutyrate and isovalerate concentrations in inoculant A-treated grain may be evidence of deamination of proline and valine, respectively (McDonalds et al., 1995). Although the low total VFA concentration of inoculant A-treated grains and the concentrate suggests that they pose the lowest acidosis risk, their high lipogenic:gluconeogenate ratio suggests that they will con- 
tribute less towards glucose synthesis, which is pivotal for the nutrient economy of animals. This low gluconeogenic potential is largely due to the extensive fermentation of the WSC in the grains by L. fermentum during the ensiling process.

\section{CONCLUSIONS}

CS was the least effective additive at preventing DM losses, yet it was the most effective treatment for curtailing proteolysis and enhancing residual WSC concentrations and aerobic stability. Among the inoculants, treatment A gave the best fermentation, followed by inoculant C. However, crimped grains conserved with inoculant A deteriorated at the fastest rate and had the lowest rate and extent of fermentation gas production. Crimped grains treated with inoculant $\mathrm{C}$ had the best chemical composition and stimulated numerically greater intakes of grass silage and total diet DM than those from any of the other treatments. It is, therefore, concluded that inoculant C, which contained L. buchneri, is a promising preservative for crimped wheat grains. This study also suggests that crimped grains can be used to replace the concentrate portion in lamb diets. Further work should confirm the applicability of these findings to dairy cows and compare the cost-benefit ratio and acidotic potential of crimped grains to that from mature, processed cereal grains.

\section{ACKNOWLEDGMENTS}

This work was funded by Lallemand Animal Nutrition, Cedex, France. The authors are grateful to Doug Bates, University of Florida, for reviewing the manuscript, and to Anne Vaughan, University of Wales, Aberystwyth, UK for conducting the laboratory analyses.

\section{REFERENCES}

Adesogan, A. T., and M. B. Salawu. 2002. Effect of applying formic acid or Lactobacillus buchneri inoculants with or without homofermentative lactic acid bacteria on the fermentation characteristics and aerobic stability of intercropped pea-wheat silages and whole crop wheat or pea silages. J. Sci. Fd. Agric. Submitted.

Charalampopoulos, D., S. S. Pandiella, and C. Webb. 2002. Growth studies of potentially probiotic lactic acid bacteria in cereal-based substrates. J. Appl. Microbiol. 92:851-859.

Czarnecka, M., Z. Czarnecki, and M. Zuromska. 1991. Effects of chemical preservation of high-moisture grain on carbohydrates and nitrogen compounds: In vitro experiments. Anim. Feed Sci. Technol. 34:343-352.
Dawson, T. E., S. R. Rust, and M. T. Yokoyama. 1998. Improved fermentation and aerobic stability of ensiled, high-moisture corn with the use of Propionibacterium acidipropionici. J. Dairy Sci. 81:10151021.

Dellaglio, F., L. M. T. Dicks, and S. Torriani. 1995. The genus leuconostoc. Pages $235-278$ in The Genera of Lactic Acid Bacteria. Vol. 2. B. J. B. Wood and W. H. Holzapfel, ed. Blackie Academic and Professional, London.

Faithfull, N. T. 1990. Acid hydrolysis prior to automatic analysis for starch. J. Sci. Food Agric. 50:419-421.

Genstat V. 1997. Genstat V for Windows. Release 4.1. Lawes Agricultural Trust. IACR Rothamsted.

Goad, D. W., C. L. Goad, and T. G. Nagaraja. 1998. Ruminal microbial and fermentative changes associated with experimentally-induced subacute acidosis in steers. J. Anim. Sci. 76:234-241.

Heron, S. J. E., R. A. Edwards, and P. Phillips. 1989. The effect of pH on the activity of ryegrass proteases. J. Sci. Food Agric. 46:267-277.

Higgins, C., and F. Brinkhaus. 1999. Efficacy of several organic acids against molds. J. Appl. Poult. Res. 8:480-487.

Hristov, A. N., M. Ivan, L. M. Rode, and T. A. McAllister. 2001. Fermentation characteristics and ruminal ciliate protozoal populations in cattle fed medium- or high-concentrate barley-based diets. J. Anim. Sci. 79:515-524.

Kung, L., and N. K. Ranjit. 2001. The effect of Lactobacillus buchneri and other additives on the fermentation and aerobic stability of barley silage. J. Dairy Sci. 84:1149-1155.

Mayne, C. S. 1993. The effect of formic acid, sulfuric acid and a bacterial inoculant on silage fermentation and the food intake and milk production of lactating dairy cows. Anim. Prod. 56:29-42.

McDonald, P., N. Henderson, and S. Heron. 1991. The Biochemistry of Silage. 2nd ed. Chalcombe Publ., Marlow, UK.

McDonald, P., R. A. Edwards, J. F. D. Greenhalgh, and C. A. Morgan. 1995. Animal Nutrition. 4th ed. Prentice Hall, Harlow.

Ministry of Agriculture, Fisheries, and Food. 1986. The Analysis of Agricultural Materials. Reference Book 427. HMSO, London.

Moon, N. J. 1983. Inhibition of the growth of acid-tolerant yeasts by acetate, lactate, propionate, and their synergistic mixtures. J. Appl. Bacteriol. 55:453-460.

Moon, N. J., L. O. Ely, and E. M. Sudweeks. 1981. Fermentation of wheat, corn, and alfalfa silages inoculated with Lactobacillus-acidophilus and candida sp. at ensiling. J. Dairy Sci. 64:807-813.

Ranjit, N. K., and L. Kung. 2000. The effect of Lactobacillus buchneri, Lactobacillus plantarum, or a chemical preservative on the fermentation and aerobic stability of corn silage. J. Dairy Sci. 83:526-535.

Salawu, M. B., T. Acamovic, C. S. Stewart, T. Hvelplund, and M. R. Weisbjerg. 1999. The use of tannins as silage additives: Effects on silage composition and mobile bag disappearance of dry matter and protein. Anim. Feed Sci. Technol. 82:243-259.

Salawu, M. B., E. H. Warren, and A. T. Adesogan. 2001. Fermentation characteristics, aerobic stability, and ruminal degradation of ensiled pea/wheat bicrop forages treated with two microbial inoculants, formic acid, or quebracho tannins. J. Sci. Food Agric. 81:1263-1268.

Shorrock, C. 1990. Ensiling early-harvested crimped grain. Pages 103105 in Milk and Meat from Forage Crops. G. E. Pollot, ed. Br. Grassl. Soc. Occasional Publ. No. 24, Reading, UK.

Weinberg, Z. G., G. Szakacs, G. Ashbell, and Y. Hen. 1999. The effect of Lactobacillus buchneri and L. plantarum, applied at ensiling, on the ensiling fermentation and aerobic stability of wheat and sorghum silages. J. Ind. Microbiol. Biotechnol. 23:218-222.

Wells, J. E., D. O. Krause, T. R. Callaway, and J. B. Russell. 1997. A bacteriocin-mediated antagonism by ruminal lactobacilli against Streptococcus bovis. FEMS Microbiol. Ecol. 22:237-243. 